\title{
Extração e Doseamento da Cafeína em Bebidas Energéticas: A Bebida TOP entre os Adolescentes!
}

$>$ Cristina Galacho

\begin{abstract}
Extraction and Determination of Caffeine in Energy Drinks. One of the Most Popular Drinks Among Teenagers! With the worldwide consumption of energy drinks increasing in recent years and documented in several international and national studies, it is crucial to increase the awareness of society, in general, and of young people, in particular, for this type of consumption and for the potential risks! This article presents a practical laboratory work that aims the extraction and determination of caffeine contents in energy drinks. The main techniques used are liquid-liquid extraction (single and multiple) and ultraviolet-visible spectrophotometry. Relevant safety aspects, relating to the solvent, are also taken into account, namely, the analysis of Physical, Health and Environmental Hazards, Hazard statements, Precautionary statements, as well as personal protective equipment, $P P E$, and collective protective equipment, CPE, based on the safety data sheets, SDS.
\end{abstract}

Perante o crescente e elevado consumo de bebidas energéticas, verificado nos últimos anos a nível mundial e documentado em diversos estudos internacionais e nacionais, é fundamental aumentar a consciencialização da sociedade, em geral, e dos jovens, em particular, para este tipo de consumo e para os seus potenciais riscos! Neste artigo é apresentado um trabalho prático laboratorial que visa a extração e doseamento da cafeína de bebidas energéticas. Como técnicas principais são usadas a extração líquido-líquido (simples e múltipla) e a espectrofotometria de ultravioleta-visível. Os aspetos relevantes de segurança, relativos ao solvente, são igualmente tidos em consideração, nomeadamente, a análise dos Perigos Físicos, para a Saúde e para o Ambiente, das Advertências de Perigo e Recomendações de Prudência, e ainda do equipamento de proteção pessoal, EPI, e coletiva, EPC, baseada nas fichas de dados de segurança, FDS.

\section{Introdução}

O que têm em comum o Café, o Chá, a Coca-Cola ${ }^{\circledR}$ e o Red Bull ${ }^{\circledR}$ ? Respondendo de forma imediata poder-se-ia dizer que são bebidas, mas há algo mais em comum... até se pode afirmar que há uma certa Química entre eles. Ah, pois há! É a cafeína...

A cafeína é um composto natural classificado como um alcaloide do grupo das metilxantinas cujo nome IUPAC é 3,7-di-hidro-1,3,7-trimetil-1H-purina-2,6-diona. Está presente de forma natural nos grãos de café e de cacau, nas folhas de chá e é adicionada a muitos outros produtos, incluindo, formulações farmacêuticas, refrigerantes do tipo "cola" e "bebidas energéticas" [1]. Uma das facetas mais conhecidas da cafeína é seguramente a de estimulante... Quem nunca bebeu um cafezinho ou uma bebida energética para se sentir mais em forma? Para além de potenciar o estado de alerta e a atenção prolongada, a cafeína apresenta numerosas vantagens reconhecidas pela ciência, tais como, ação antioxidante, efeito diurético, promoção da utilização da gordura corporal durante a prática de exercício físico, etc. A sensibilidade à cafeína varia muito de indivíduo para indivíduo e, quando consumida em excesso, pode causar efeitos indesejáveis, nomeadamente, ansiedade, agitação e inquietação, insónias, distúrbios gastrointestinais, entre outros $[1,2]$.

Na Tabela 1 apresenta-se, a título informativo, o teor de cafeína em diferentes bebidas presentes no nosso quotidiano, incluindo, o das cada vez mais populares bebidas energéticas [1-5]. 
Tabela 1 - Teor de cafeína em diferentes bebidas presentes no nosso quotidiano [1-5].

\begin{tabular}{|c|c|c|}
\hline Bebida & Quantidade / mL & Teor em cafeína / mg \\
\hline Café "curto" & 17 & 62 \\
\hline Café "médio" & 28 & 72 \\
\hline Café "cheio" & 47 & 88 \\
\hline Chá preto saqueta (infusão 1-3 min) & 150 & $15-35$ \\
\hline Chá preto saqueta (infusão 3-5 min) & 150 & $30-50$ \\
\hline Chá (folhas) & 150 & $20-30$ \\
\hline Refrigerantes tipo cola & 330 & $30-48$ \\
\hline RedBull ${ }^{\circledast}$ Energy Drink & 250 & 80 \\
\hline Monster Energy ${ }^{\circledR}$ & 250 & 80 \\
\hline HELL Strong Red Grape ${ }^{\oplus}$ & 250 & 96 \\
\hline Chocolate Quente & 240 & 10 \\
\hline
\end{tabular}

As bebidas energéticas correspondem a um grupo de bebidas não alcoólicas com um elevado teor de cafeína e às quais são adicionadas outras substâncias, nomeadamente hidratos de carbono (glucoronolactona, dextrose, sacarose), aminoácidos (taurina), vitaminas do grupo B (riboflavina (B2), ácido nicotínico (B3), piridoxina (B6), cianocobalamina (B12)), aminas (L-carnitina) e extratos de plantas (ginseng, guaraná), entre outras [3-8].

O consumo deste tipo de bebidas, isoladas ou combinadas com álcool, tem vindo a aumentar de forma exponencial nos últimos anos e é cada vez mais popular entre os jovens [6-8]. Os objetivos predominantes para este tipo de consumo são a obtenção de mais energia e o aumento da concentração, para diversos fins, como, por exemplo, estudar, performance física e diversão [6-8]. Um estudo de 2011 da Autoridade Europeia para a Segurança dos Alimentos (EFSA), realizado em 16 países europeus, revelou que $68 \%$ dos adolescentes com idades compreendidas entre os 10-18 anos, 30\% dos adultos e $18 \%$ das crianças com idade inferior a 10 anos consumiam bebidas energéticas [9]. Em Portugal, o consumo de bebidas energéticas está ainda pouco estudado. Em 2014, a Autoridade de Segurança Alimentar e Económica (ASAE) realizou um estudo no distrito de Lisboa, análogo ao da EFSA, tendo verificado o consumo de bebidas energéticas em $42 \%$ dos adolescentes [10]. Posteriormente, o artigo "Bebidas Energéticas: Qual a realidade na adolescência?" publicado em 2017 na revista da Sociedade Portuguesa de Pediatria divulgou que $76 \%$ dos adolescentes com idades compreendidas entre os 14-17 anos já tinham experimentado bebidas energéticas, tendo a primeira ingestão ocorrido entre os 12 e os 15 anos em $85 \%$ dos casos [6].

A crescente popularidade destas bebidas entre os jovens levou algumas organizações, como a Organização Mundial da Saúde (OMS), a alertar para os seus efeitos prejudiciais e a recomendar que estas não sejam consumidas por crianças e adolescentes. Entre os vários efeitos adversos das bebidas energéticas estão a taquicardia, agitação, cefaleia, insónia, desidratação, tonturas, ansiedade, irritabilidade, tremores, aumento da pressão arterial e distúrbios gastrointestinais $[6,9,10]$. A OMS alertou ainda para o facto de que outros ingredientes das bebidas energéticas, como os estimulantes e aditivos, não terem sido estudados em profundidade o que implica que os seus efeitos a curto e a longo prazo não sejam totalmente conhecidos e que, associados à cafeína, poderão ser potenciados [6]. Um estudo mais recente, publicado em 2019 no Journal of American Heart Association, corrobora alguns dos efeitos adversos destas bebidas concluindo que as bebidas energéticas efetivamente alteram a atividade cardiovascular e aumentam a pressão arterial [11].

A realidade é que os jovens em todo o mundo consomem cada vez mais, e em quantidades excessivas, este tipo de bebidas, apesar dos potenciais efeitos adversos! Assim, é fundamental aumentar a consciencialização da sociedade, em geral, e das crianças e adolescentes, em particular, para este tipo de consumo e para os seus riscos! Extrair e Dosear para Consciencializar e reduzir o consumo no dia-a-dia!

\section{Descrição global do trabalho prático laboratorial}

O trabalho prático laboratorial apresentado permite aos estudantes de 1. ciclo das Licenciaturas em Química e afins extrair e dosear o teor de cafeína em bebidas energéticas, consciencializando para este tipo de consumo e para os seus potenciais riscos. Os objetivos principais são aquisição de conceitos e competências relativos à técnica de extração líquido-líquido (simples e múltipla), enquanto operação unitária utilizada em Química Laboratorial, e à espectrofotometria de ultravioleta-visível, enquanto técnica de análise quantitativa. Não menos importante são as competências desenvolvidas e a aprendizagem de conceitos fundamentais relativos à segurança em laboratórios.

Este trabalho foi planeado para a unidade curricular "Técnicas e Métodos de Laboratório I" (1.`ano) das Licenciaturas em Química, Bioquímica, Biotecnologia e Biologia Humana da Universidade de Évora. Tem a duração total de 180 minutos, dos quais cerca de 120 são destinados à realização do procedimento experimental, efetuado por grupos de três estudantes. 0 número ideal de grupos por turma é de 4 ( 12 estudantes) podendo ir até aos 5 (15 estudantes), dependendo das dimensões do laboratório e do EPC (Equipamento de Proteção Coletiva) disponível, nomeadamente do número de hottes. 0 trabalho pode também ser realizado por alunos do 12. ano da área de Ciências e Tecnologias que frequentem a disciplina de Química, desde que estejam reunidas todas as condições de segurança laboratorial. 


\section{Protocolo Experimental}

\section{Amostra a analisar \\ - Bebida energética corada (previamente desgaseificada por agitação mecânica, à temperatura ambiente): Redbull Red Edition (cafeína: 32 mg / 100 mL).}

\section{Solventes e soluções}

- Clorofórmio puro (Labsolve 99,93\%).

- Solução de cafeína (Acros Organics, 98,5\%) em clorofórmio 0,20 g/L.

\section{Equipamento}

- Espectrofotómetro de absorção molecular no UV-Vis (Nicolet Evolution 300).

- Células de quartzo (l= $1 \mathrm{~cm})$ com tampa.

\section{Segurança: Equipamentos de Proteção Individual (EPI) e Coletiva (EPC) \\ -EPI: Bata, luvas e óculos de proteção. -EPC: Hottes.}

\section{Procedimento experimental}

Trabalhar em laboratório com um bom sistema de ventilação e na hotte sempre que utilizar clorofórmio.

\subsection{Preparação das soluções padrão de cafeína a partir da solução de concentração $0,20 \mathrm{~g} / \mathrm{L}$}

- A uma série de cinco balões volumétricos de 25,0 mL, devidamente identificados, adicionar, respetivamente, 0,5, 1,0, 2,0, 4,0 e 6,0 mL da solução de cafeína 0,20 $\mathrm{g} / \mathrm{L}$, medidos com pipeta ou micropipeta.

- Perfazer o volume com clorofórmio.

- Homogeneizar as soluções.

\subsection{Extração da cafeína da bebida energética}

\subsubsection{Extração simples}

- Medir, com pipeta volumétrica, 5,0 mL da bebida energética previamente desgaseificada para a ampola de extração.

- Adicionar, com pipeta graduada, 15,0 mL de clorofórmio e proceder à extração recolhendo a fase mais densa para um balão de $50 \mathrm{~mL}$.

- Perfazer o volume com clorofórmio.

- Homogeneizar e identificar a solução.

\subsubsection{Extração múltipla}

- Medir, com pipeta volumétrica, 5,0 mL da bebida energética previamente desgaseificada para a ampola de extração.
- Adicionar, com pipeta volumétrica, 5,0 mL de clorofórmio e proceder à extração, recolhendo a fase mais densa para um balão de $50 \mathrm{~mL}$.

- Repetir a extração por mais duas vezes com volumes de 5,0 mL de clorofórmio, recolhendo a fase mais densa no balão de $50 \mathrm{~mL}$ usado na primeria extração. - Perfazer o volume com clorofórmio.

- Homogeneizar e identificar a solução.

\subsection{Doseamento da cafeína na bebida energética}

\subsubsection{Traçado da curva de calibração}

- Proceder à leitura dos valores de absorvância das soluções padrão a $278 \mathrm{~nm}$.

\subsubsection{Doseamento da cafeína}

- Proceder à leitura dos valores de absorvância das soluções contendo os extratos de cafeína da bebida energética a $278 \mathrm{~nm}$.

\section{Tratamento de resultados}

- Calcular a concentração das soluções padrão de cafeína preparadas em 5.1, expressa em mg/L.

- Traçar a curva de calibração absorvância versus concentração das soluções padrão de cafeína.

- Considerar a gama da curva de calibração onde a resposta da absorvância versus concentração é linear. Determinar os parâmetros da equação de calibração linear. - Apresentar a equação que relaciona a absorvância e a concentração em cafeína.

- Determinar o teor de cafeína, expresso em $\mathrm{mg} / \mathrm{L}$, da bebida energética analisada e comparar com o valor do rótulo.

- Comparar os dois processos de extração.

\section{Resultados e discussão}

\section{Elaboração da curva de calibração}

Para a elaboração da curva de calibração foram preparadas cinco soluções padrão de cafeína em clorofórmio, de concentração 4, 8, 16, 32 e 48 mg/L, a partir da solução de cafeína em clorofórmio de concentração 0,20 g/L. A determinação do valor de absorvância de cada uma destas soluções foi efetuada ao comprimento de onda de $278 \mathrm{~nm}$, correspondente ao máximo de absorvância da cafeína no referido solvente. A utilização de um espectrofotómetro de feixe duplo implicou a colocação do solvente usado na preparação de todas as soluções, clorofórmio, 
na célula de referência. Na Tabela 2 apresentam-se os valores de concentração das soluções padrão de cafeína, expressos em mg/L, e os respetivos valores de absorvância, medidos a $278 \mathrm{~nm}$. A reta de calibração para a determinação do teor de cafeína em bebidas energéticas apresenta-se na Figura 1.

Tabela 2 - Concentração das soluções padrão e respetivos valores de absorvância.

\begin{tabular}{|c|c|c|}
\hline Solução padrão & $\begin{array}{c}\text { [Solução Padrão] } \\
\text { / } \text { mgL }^{-1}\end{array}$ & $\begin{array}{c}\text { Absorvância } \\
\text { / 278 nm }\end{array}$ \\
\hline 1 & 4 & 0,2218 \\
2 & 8 & 0,4497 \\
3 & 16 & 0,8702 \\
4 & 32 & 1,7476 \\
5 & 48 & 2,5765 \\
\hline
\end{tabular}

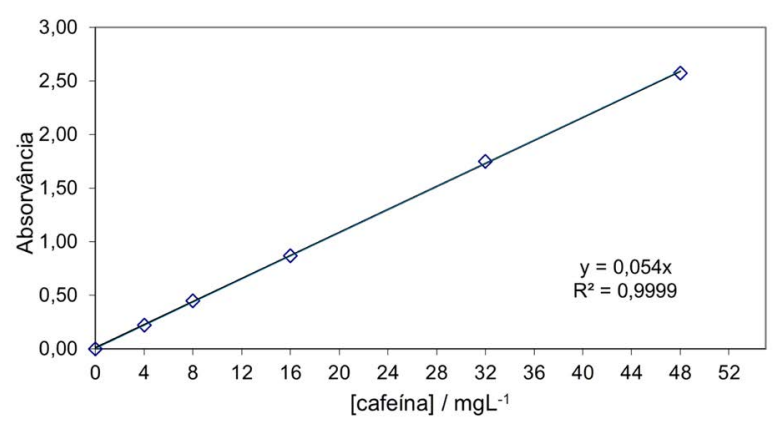

Figura 1 - Reta de calibração para a determinação do teor de cafeína em bebidas energéticas.

A análise dos resultados obtidos, por regressão linear simples, permitiu estabelecer a equação 1 , que relaciona absorvância (a 278 nm) e concentração em cafeína (em mg'-1).

Absorvância $(278$ nm) = 0,054 [Cafeína]

A relação linear é válida para a gama de concentrações estudadas, 4-48 $\mathrm{mg}^{-1}$, verificando-se a aplicabilidade da Lei de Beer-Lambert, $A=\varepsilon / c$, onde $A$ é a absorvância, $\varepsilon$ a absortividade molar, I o percurso ótico e c a concentração.

\section{Determinação do teor em cafeina na bebida energética analisada}

Com base na equação 1 e nos valores de absorvância típicos obtidos para os extratos da bebida energética analisada, apresentados na Tabela 3, determinou-se o teor em cafeína expresso em $\mathrm{mg}^{\mathrm{L}} \mathrm{L}^{-1}$ e em percentagem massa/volume (\% m/V). A expressão dos resultados em percentagem massa volume permitiu a comparação direta com os valores constantes no rótulo da bebida.
Tabela 3 - Bebida energética analisada e respetivos valores de absorvância dos extratos obtidos por extração simples e múltipla.

\begin{tabular}{|c|c|c|c|c|}
\hline Bebida & Processo de extração & Absorvância & $\begin{array}{c}\text { Teor em Cafeína } \\
\mathrm{mgL}^{-1}\end{array}$ & $\begin{array}{c}\text { Teor em Cafeína } \\
\%(\mathrm{~m} / \mathrm{V})\end{array}$ \\
\hline \multirow{2}{*}{$\begin{array}{c}\text { Redbull } \\
\text { Red Edition }\end{array}$} & $\begin{array}{c}\text { Simples } \\
(1 \times 15 \mathrm{~mL} \text { clorofórmio })\end{array}$ & 1,5440 & 28,6 & 28,6 \\
\cline { 2 - 5 } & $\begin{array}{c}\text { Múltipla } \\
(3 \times 5 \mathrm{~mL} \text { clorofórmio })\end{array}$ & 1,6435 & 30,4 & 30,4 \\
\hline
\end{tabular}

\section{Comparação dos resultados obtidos com o valor rotulado e avaliação da eficiência dos processos de extração}

A comparação dos resultados obtidos com o valor expresso no rótulo da bebida energética analisada, Redbull Red Edition, 32 mg de cafeína por 100 mL, permite efetuar uma análise dos dois processos de extração utilizados, verificando-se que o processo de extração múltipla, realizado com três frações de 5,0 $\mathrm{mL}$ clorofórmio, é mais eficiente do que o processo de extração simples, realizado uma única vez com o volume total de solvente, $15 \mathrm{~mL}$. 0 processo de extração múltipla permite extrair 95\% da cafeína presente no Redbull enquanto que o processo de extração simples apenas permite extrair $89 \%$ da cafeína existente. Considerando, como parâmetros, a rapidez de execução, a facilidade de execução e a eficiência, ambos os processos se revelaram adequados para o objetivo em causa: Extrair e Dosear para Consciencializar e reduzir o consumo no dia-a-dia!

\section{Segurança e sustentabilidade}

A utilização do clorofórmio como solvente das soluções padrão de cafeína e do processo de extração líquido- líquido implica a identificação dos perigos associados ao mesmo, assim como o conhecimento dos primeiros socorros e do controlo da exposição/proteção individual. Assim, antes da realização do trabalho prático laboratorial, é imprescindível que todos os estudantes envolvidos tenham pesquisado na internet e lido uma ficha de dados de segurança do clorofórmio, nomeadamente a informação constante das seções 2, 4 e 8 . Devem ter conhecimento dos pictogramas de perigo e do seu significado, das advertências de perigo ( $\mathrm{Hxxx}$ ) e das recomendações de prudência de prevenção (P2xx) e de resposta (P3xx), das medidas de primeiros socorros e do equipamento de proteção individual, EPI, adequado. A ficha de dados de segurança do clorofórmio, pesquisada e consultada, deve estar atualizada e conforme o estabelecido no CLP (Regulamento CE n. ${ }^{\circ}$ 1272/2008 do Parlamento Europeu e do Conselho relativo à classificação, rotulagem e embalagem de substâncias e misturas) [12,13]. Durante a realização do trabalho prático laboratorial é obrigatório o uso de bata, luvas e óculos e trabalhar na hotte sempre que indicado no protocolo experimental. 
A utilização do clorofórmio como solvente das soluções padrão de cafeína e do processo de extração líquido- líquido não está parcialmente em linha com o quinto Princípio da Química Verde, PQV5. Este princípio refere que o uso de substâncias auxiliares (solventes, agentes para promover separações, etc.) deve ser evitado sempre que possível e, quando usados, esses agentes devem ser inócuos [14]. Adicionalmente, uma das metas do objetivo 3 de desenvolvimento sustentável, ODS 3, constante na Agenda 2030 da Organização das Nações Unidas, visa reduzir substancialmente, até 2030, o número de mortes e doenças devido a químicos perigosos, contaminação e poluição do ar, da água e do solo [15]. Assim, este trabalho proporciona ainda uma oportunidade para uma breve introdução às temáticas da Química Verde e da Agenda 2030 da Organização das Nações Unidas para o Desenvolvimento Sustentável. Estes temas são atuais, pertinentes e prementes para os jovens do século XXI e para a sustentabilidade do planeta Terra!

\section{Conclusões}

0 trabalho prático laboratorial proposto permite aos estudantes de $1 .^{\circ}$ ciclo das Licenciaturas em Química e afins extrair e dosear o teor de cafeína em bebidas energéticas, consciencializando para este tipo de consumo e para os seus potenciais riscos. Os objetivos principais são aquisição de conceitos e competências relativos às técnicas de extração líquido-líquido (simples e múltipla) e espectrofotometria de ultravioleta-visível, enquanto técnica de análise quantitativa. Não menos importante são as competências desenvolvidas e a aprendizagem de conceitos fundamentais relativos à segurança em laboratórios. A pesquisa da ficha de dados de segurança do clorofórmio e a leitura obrigatória das seções 2 , 4 e 8 permitem ter conhecimento dos pictogramas de perigo e do seu significado, das advertências de perigo ( $H x x x)$ e das recomendações de prudência de prevenção (P2xx) e de resposta (P3xx), das medidas de primeiros socorros e do equipamento de proteção individual, EPI, adequado. Esta metodologia deve ser assimilada e adotada, em trabalhos futuros. A utilização de EPI permite ainda experienciar a realização de trabalho experimental com luvas e óculos de proteção, preparando os estudantes para trabalhos futuros com maior exigência ao nível de segurança laboratorial. A oportunidade para uma breve referência às temáticas da Química Verde e da Agenda 2030 da Organização das Nações Unidas para o Desenvolvimento Sustentável é bastante pertinente para os jovens do século XXI e para a sustentabilidade do planeta Terra!

\section{Referências}

[1] C. Galacho, P. J. Mendes "A Cafeína" Semanário Registo. Edição 210 08/06/2012 http://www.registo.com.pt/cultura/a-cafeina/\#.UO rSazDVks (acedido em 22/01/2020).

[2] C. Galacho, P. J. Mendes "Mais Cafeína" Semanário Registo. Edição 212 20/06/2012 http://www.registo.com.pt/cultura/mais-cafeina/\#.UO_ riKzDVkt (acedido em 22/01/2020).

[3] Redbull Portugal energydrink-pt.redbull.com/p\%C3\%A1gina-davis\%C3\%A3o-geral-dos-ingredientes-da-red-bull-energy-drink (acedido em 31/01/2020).

[4] Hell Energy Drink. hellenergy.com/products (acedido em 31/01/2020).

[5] Monster Energy. monsterenergy.com/pt/pt_pt/products/monster-energy (acedido em 31/01/2020).

[6] L. Branco, F. F. Lima, C. Ferreira, L. Macedo, C. Laranjeira, Acta Pediatr. Port. 2017, 48, 109-117. DOI: 10.25754/pjp.2017.7634.

[7] Como as bebidas energéticas afetam o organismo, in SIC Notícias. sicnoticias.pt/mundo/2019-05-29-Como-as-bebidas-energeticasafetam-o-organismo (acedido a 22/01/2020).

[8] Jovens consomem muitas bebidas energéticas, apesar dos efeitos adversos, in Jornal Público. https://www.publico.pt/2017/06/05/sociedade/noticia/ bebidas-energeticas-jovens-portugueses-bebem-muito-apesar-dospotenciais-efeitos-adversos-1774604 (acedido a 22/01/2020)

[9] J. Breda, S. H. Whiting, R. Encarnação, S. Norberg, R. Jones, M. Reinap, J. Jewell, Frontiers in Public Health 2014, 134, 1-5. DOI: 10.3389/fpubh.2014.00134.

[10] S. S. Gaspar, M.M. Mendes, F. Ramos, Riscos Alimentos 2014, 8, 4-49.

[11] S. A. Shah, A. H. Szeto, R. Farewell, A. Shek, D. Fan, D. K. N. Quach, M. Bhattacharyya, J. Elmiari, B. W. Chan; K. O'Dell, N. Nguyen, T. J. McGaughey, J. M. Nasir, S. Kaul, J. Am. Heart Assoc. 2019, 8, 1-14. DOI:10.1161/JAHA.118.011318.

[12] C. Galacho, Química BSPQ 2015, 138, 47-56.

[13] Ficha de dados de segurança do Clorofórmio, Solvay. solvay.pt > cloroformio_A20_PT-161390 (acedida em 20/01/2020).

[14] P. T. Anastas, J. C. Warner "Green Chemistry - Theory and Practice" Oxford U.P., Oxford, 1998.

[15] Guia sobre Desenvolvimento Sustentável - UNRIC.org https://unric.org/pt/ objetivos-de-desenvolvimento-sustentavel (acedido em 20/01/2020).

\section{Cristina Galacho}

É licenciada em Química Tecnológica pela FCUL e Doutorada em Química pela Universidade de Évora (UÉ). É Professora Auxiliar do Departamento de Química da Escola de Ciências e Tecnologia da UÉ e Investigadora do Laboratório HERCULES. É formadora acreditada pelo Conselho Científico-Pedagógico da Formação Contínua (CCPFC) e autora de ações de formação destinadas a Professores do grupo 510. pcg@uevora.pt CIÊNCIA ID: 5516-15D2-AA6D 